
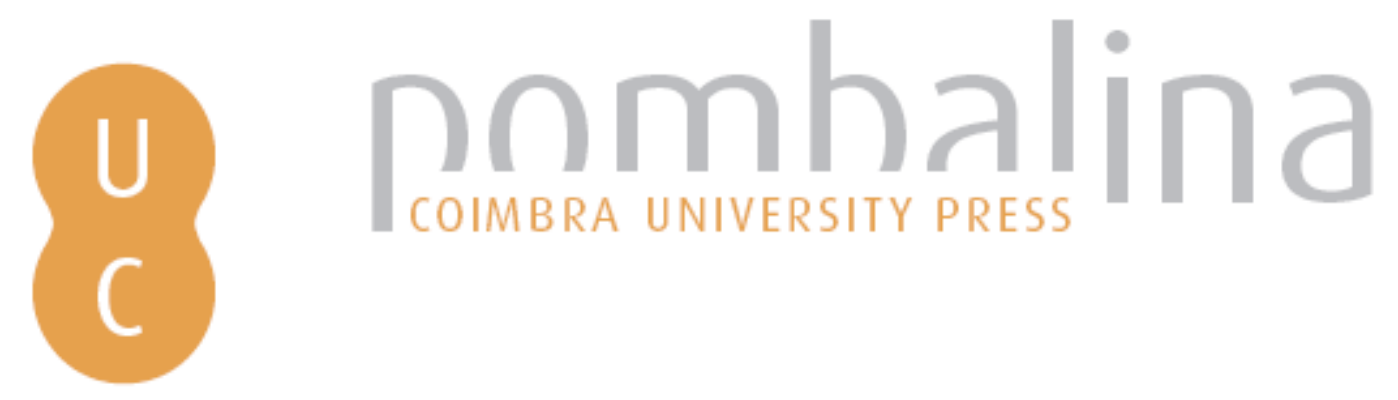

Turismo: um espelho da(s) realidade(s) contemporânea(s): do mundo globalizado à globalização do medo e da insegurança
Autor(es):
Brito, Mónica Morais de
Publicado por: Imprensa da Universidade de Coimbra
URL
persistente:
URI:http://hdl.handle.net/10316.2/43529
DOI:
DOI:https://doi.org/10.14195/978-989-26-1343-7_33
Accessed : $\quad$ 26-Apr-2023 12:58:00

A navegação consulta e descarregamento dos títulos inseridos nas Bibliotecas Digitais UC Digitalis, UC Pombalina e UC Impactum, pressupõem a aceitação plena e sem reservas dos Termos e Condições de Uso destas Bibliotecas Digitais, disponíveis em https://digitalis.uc.pt/pt-pt/termos.

Conforme exposto nos referidos Termos e Condições de Uso, o descarregamento de títulos de acesso restrito requer uma licença válida de autorização devendo o utilizador aceder ao(s) documento(s) a partir de um endereço de IP da instituição detentora da supramencionada licença.

Ao utilizador é apenas permitido o descarregamento para uso pessoal, pelo que o emprego do(s) título(s) descarregado(s) para outro fim, designadamente comercial, carece de autorização do respetivo autor ou editor da obra.

Na medida em que todas as obras da UC Digitalis se encontram protegidas pelo Código do Direito de Autor e Direitos Conexos e demais legislação aplicável, toda a cópia, parcial ou total, deste documento, nos casos em que é legalmente admitida, deverá conter ou fazer-se acompanhar por este aviso.

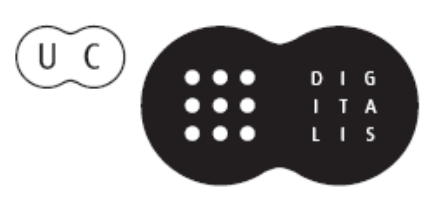




\section{FERNANDA CRAVIDÃO}

\section{IÚCIO CUNHA}

PAULA SANTANA

\section{NORBERTOSANTOS}

(ORG.)

\section{ESPAÇOS E TEMPOS EM GEOGRAFIA}

HOMENAGEM A ANTÓNIO GAMA

IMPRENISA DÁ UNIVERSIDADE DE COIMBRA COIMBRA UNIVERSITY PRESS

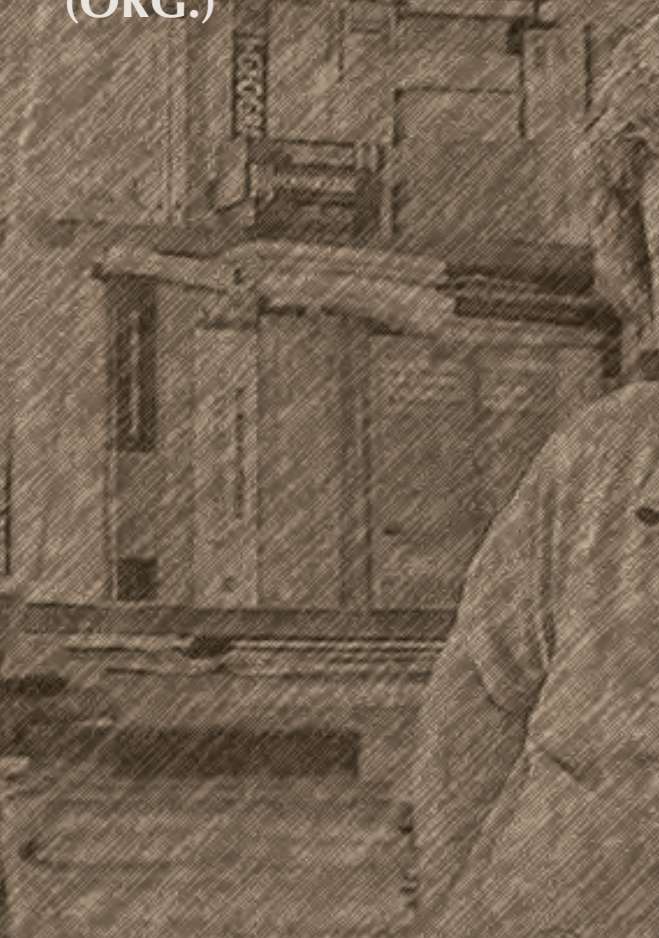




\title{
TURISMO: UM ESPELHO DA(S) REALIDADE(S) CONTEMPORÂNEA(S) - DO MUNDO GLOBALIZADO À GLOBALIZAÇÁO DO MEDO E DA INSEGURANÇA
}

\author{
Mónica Morais de Brito/monicabrito71@gmail.com \\ Departamento de Geografia e Turismo \\ da Faculdade de Letras da Universidade de Coimbra \\ e CEGOT - Centro de Estudos de Geografia \\ e Ordenamento do Território
}

Nota

Este é um pequeno contributo para a reflexão sobre um tema que, na atualidade, invade o quotidiano de todos nós. Mas pretende ser mais do que isso. É uma tentativa de cruzar os meus interesses de investigação com aqueles de que me apercebi, ainda que muito superficialmente, e num curto espaço de tempo, serem também os do colega António Gama. Substituí-o na lecionação da disciplina de Geografia e Organizaçóes Internacionais, um desafio que enfrentei com a sua ajuda e completa generosidade e, também aí, fiz um exercício semelhante. Espero, em honra da sua memória, da pessoa que foi, e do legado que deixou, ter sido bem-sucedida no passado e também agora neste empreendimento.

\section{Introdução}

A sensação de sermos cidadãos do mundo confere uma dimensão de omnipresença à nossa vivência quotidiana. A distância psicológica entre as diversas 
geografias reduziu-se drasticamente. A distância física mede-se, hoje, não em quilómetros ou em milhas, mas em tempo. O conceito de fronteira alterou-se significativamente, e a perceçáo de que estamos a poucas horas de quase tudo amplia o nosso universo de expectativas pessoais, profissionais e também de lazer.

Este conjunto de sensaçóes, perceçóes e realidades sobre o espaço e o tempo resultam da evolução tecnológica, mas também de um conjunto de profundas mudanças políticas, sociais e culturais que em muito contribuíram para a alteração do sistema-mundo, mas também das mentalidades e das nossas próprias escalas. $\mathrm{O}$ século $\mathrm{xx}$, sobretudo nas últimas três décadas, foi rico em inovação, nas Tecnologias de Informação e Comunicação, nos transportes e vias de comunicaçáo, mas também em eventos marcantes como a queda do muro de Berlim (1989), o colapso da URSS (1991), o Tratado de Maastricht (1992), e as suas consequências na livre circulação de pessoas, e o surgimento do Espaço Schengen em 1985, entre outros.

Diretamente relacionado com esta realidade física e virtual surge o conceito de globalização, que invadiu o discurso quotidiano: o dos cidadáos comuns, o dos governantes e o dos políticos, entre outros. Pela sua complexidade, pela sua aparente novidade, suscita diferentes opiniōes e posiçóes, umas mais extremadas do que outras, sobre um processo, um fenómeno que alguns defendem ter começado com a epopeia dos descobrimentos portugueses, embora com contornos muito distintos dos atuais. Na prática, a globalizaçáo estende-se a múltiplas dimensôes da realidade, nomeadamente à geopolítica, à universalização de determinados idiomas, à cultura, no seu sentido mais amplo (preferências estéticas, movimentos artísticos, vestuário, hábitos de consumo) e, inclusive à homogeneização de algumas paisagens especialmente as ocidentais (Font e Rufí, 2006: 36).

Este cenário, mesclado de nuances positivas, não se esgota na abordagem otimista, pois a globalização, nas suas múltiplas dimensôes, como a mobilidade e a proximidade física e virtual, têm igualmente aspetos negativos, permitindo a circulação de pessoas, de bens e de informação para fins perversos, colocados ao serviço de ideais deturpados que se focam no fomento do terror e na propagação da ideologia do medo, à escala global, com os respetivos impactos, nomeadamente económicos. Por outro lado, as incertezas e as inseguranças 
de natureza económica e social refletem-se igualmente à escala mundial, independentemente do seu epicentro, sendo tanto maior o seu impacto quanto maior o protagonismo do país ou países envolvidos, podendo citar-se, a título de exemplo, o Brexit no Reino Unido.

McLuhan (1972) introduziu o conceito de Aldeia Global, relacionado com o de globalização, e que traduz uma nova visão do mundo como consequência do desenvolvimento das TIC’s e da evoluçáo dos transportes, e que tem subjacente um conjunto de desafios, tangíveis e intangíveis, que impóem uma predisposição contínua para a mudança. Para além da mudança de mentalidades, a vivência nesta Aldeia Global, obriga a um comportamento simultaneamente reativo e pró-ativo por parte de cada um dos territórios, seja qual for a escala considerada, que permita defender a sua individualidade e identidade sem contudo ignorar as ameaças e as oportunidades inerentes a esta realidade.

No caso particular do Turismo, uma das atividades económicas mundialmente mais expressivas, pelas receitas e pelos postos de trabalho, geradas direta e indiretamente, a relaçáo biunívoca com os conceitos de globalizaçáo, e de mobilidade física e virtual, é inquestionável. A análise diacrónica dos impactos da evoluçáo dos transportes e das tecnologias de comunicação e informaçáo no turismo, e a reciprocidade deste processo, permite-nos constatar que o incremento da procura turística é, simultaneamente, um produto e um catalisador desse mesmo processo de evoluçáo. Por um lado, a facilidade de circulaçấo das pessoas à escala global é o resultado gradual da evolução dos transportes, o surgimento do comboio, do carro, do barco, do avião, nas suas múltiplas modalidades, são marcos importantes também na história do Turismo, incrementando fortemente a procura interna, mas sobretudo a externa. As TIC's, por outro lado, viabilizaram a inovação na comunicaçáo e no marketing, permitindo novas estratégias, a conquista de novos mercados e uma maior autonomia na escolha dos destinos e na preparação das viagens por parte dos visitantes, transpondo para o Turismo o conceito de Aldeia Global. No entanto, esta evoluçáo tem também subjacente uma carga negativa, pois pelas suas características, pela sua natureza sistémica, o Turismo é um setor sensível, continuamente exposto a eventos como guerras, epidemias, terrorismo, crises económicas, entre outros, 
potenciados pela proximidade física e virtual do mundo atual. Por esta razão, e também porque o perfil do turista se tem vindo a sofisticar, a segurança é um fator crescentemente valorizado, tendo assumido uma nova dimensão após os ataques terroristas de 11 de setembro de 2001, nos Estados Unidos da América, e tiveram um impacto muito significativo na indústria do turismo, na economia, nas perceçóes de viagem, entre outros.

$\mathrm{Na}$ realidade, existem inúmeros acontecimentos naturais e humanos que constituem verdadeiras ameaças aos fluxos turísticos, às economias e à sustentabilidade e autossustentação dos destinos. Neste grupo integram-se os crimes (roubos, assassínios, raptos), os conflitos étnicos, os aspetos sanitários (águas não potáveis, intoxicações, doenças), os desastres naturais (tufốes, sismos, vulcóes...), conflitos políticos, terrorismo e a guerra (Bentley e Page, 2001). Normalmente, a instabilidade e a insegurança surgem quase sempre associadas a destinos turísticos mais baratos, que se encontram estigmatizados devido a esses problemas. Por exemplo Roma e Hong Kong têm uma imagem negativa conectada com o número recorde de crimes cometidos contra turistas. No conjunto das questóes da segurança também surgem os desastres naturais, e embora o seu impacte sobre as decisóes dos turistas tenha um período mais curto, comparativamente aos induzidos pelo homem, podendo até constituir uma atração turística, o certo é que pesam nas escolhas dos turistas pelo menos a curto prazo (Tymothy, 2006).

Pelos motivos anteriormente elencados, a segurança e a estabilidade, nas suas múltiplas dimensões, são fatores a rentabilizar aquando do planeamento e dos destinos turísticos. Territórios com vocação turística com uma imagem positiva a este nível são cada vez mais competitivos, pois muitos dos destinos turísticos mundiais mais maduros situam-se em países muito propensos a atos de terrorismo, com elevado nível de criminalidade, e em que não existem garantias quanto à vida e à integridade do turista, podendo citar-se, a título de exemplo, França, Inglaterra, mas também o Brasil.

No caso particular desta abordagem, o objetivo principal é analisar as consequências para os destinos turísticos, mas também para os diferentes stakeholders do sistema turístico, do terrorismo, a partir dos últimos acontecimentos ocorridos a este nível à escala mundial, de forma a relacionar estas 
duas variáveis, num quadro teórico encimado pelos conceitos de Globalizaçấo e de Aldeia Global, fenómenos intangíveis de impactos tangíveis, que definem a atualidade do mundo em que vivemos.

Terrorismo e turismo: que relação?

\section{Turismo: presente e futuro}

O turismo tem vindo a assumir um papel cada vez mais relevante no crescimento económico e no desenvolvimento à escala mundial, sendo responsável por um número crescente de viagens internacionais e de receitas. De acordo com a WTO - World Tourism Organization (2016) o número de chegadas de turistas internacionais, em 2015, foi de 1186 milhôes (Figura 1), o que representa um aumento de 52 milhóes, cerca de 5\%, relativamente ao ano transato. Um comportamento que se verifica pelo sexto ano consecutivo, apesar da crise económica que deflagrou em 2009, e das suas múltiplas consequências.

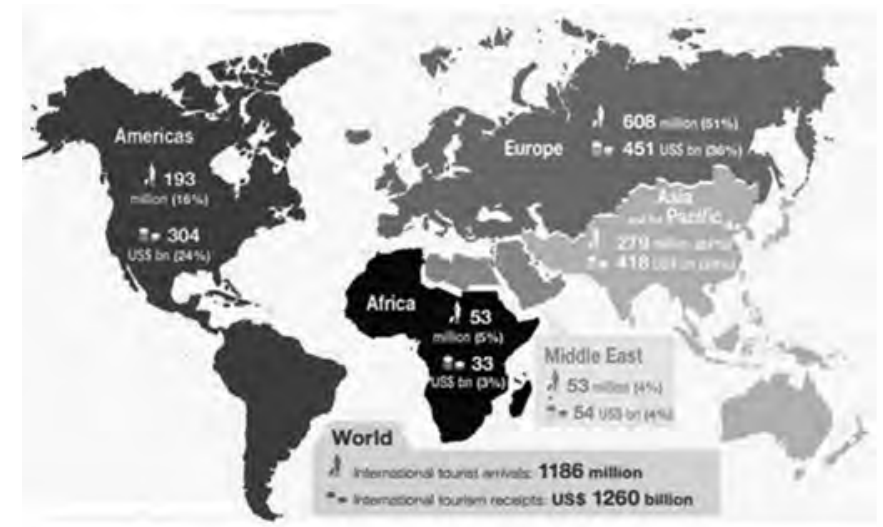

Turismo Internacional em 2015

Fonte: WTO, 2016. 
De acordo com as previsões da WTO (Figura 2), esta tendência manter-se-á nas próximas décadas, perspetivando-se que o número de chegadas de turistas internacionais apresente um aumento médio de 3,3\% ao ano, entre 2010 e 2030. Em termos absolutos, o número de chegadas de turistas internacionais irá aumentar cerca de 43 milhóes por ano, um valor muito superior ao verificado entre 1995 e 2010 , em que se assistiu a um aumento médio de 28 milhóes por ano (WTO, 2016).

Ainda que o comportamento turístico das diferentes regióes seja heterogéneo, o presente e o futuro do turismo, em função do número de viagens internacionais e das receitas geradas por essa via, é de afirmação crescente. No entanto, pelas suas próprias características e também pelo seu crescente protagonismo, o Turismo apresenta um conjunto de vulnerabilidades de natureza pouco controlável, entre as quais se destaca o terrorismo, pelo facto dos destinos e das atividades turísticas serem alvos atraentes para estes atos, como também pelos impactos indiretos dos atentados na procura turística dos territórios onde ocorrem.

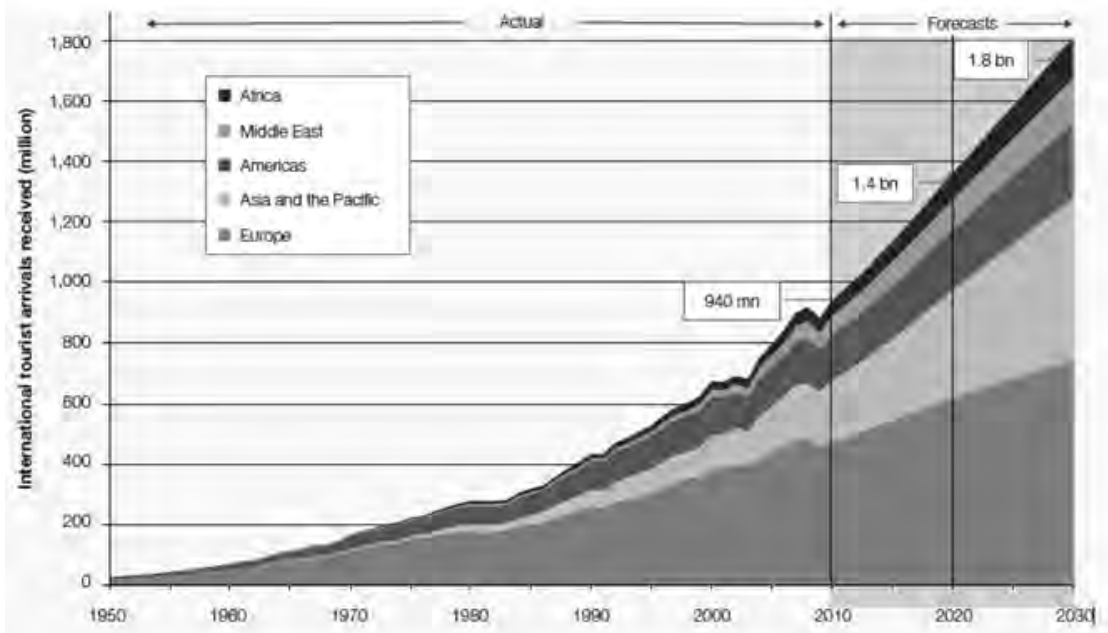

Figura 2

Evolução e tendências do Turismo 1950-2013

Fonte: WTO, 2016. 


\section{O impacto do terrorismo no turismo: abordagem conceptual}

As crises e os desastres com impactos no turismo estão a intensificar-se de forma extremamente acentuada (Faulkner, 2001 apud Brent et al, 2004: 3). Esta perceção partilhada pelos vários stakeholders envolvidos no sistema turístico e pelos próprios investigadores, ainda não se traduziu num conhecimento teórico-prático que permita uma avaliação profunda dos seus impactos, bem como a sua prevenção e gestão eficiente aquando da ocorrência dos inúmeros eventos que têm ocorrido à escala global. Aliás, Lee e Harrald (1999 apud Brent et al, 2004: 4) referem como surpreendente a falta de interesse que esta temática tem despertado, considerando que a gestão de crises deverá ser uma competência presente no perfil de qualquer indivíduo que desenvolva a sua atividade profissional no âmbito do planeamento e da gestão do Turismo.

$\mathrm{Na}$ atualidade, e passada mais de uma década sobre a análise dos autores referenciados, o mundo e o comportamento do cidadão comum, e em particular dos profissionais ligados ao planeamento e à gestão do Turismo, alterou-se significativamente, pois inúmeras ocorrências, nomeadamente guerras e atentados terroristas, mas também catástrofes naturais, impuseram preocupações acrescidas e novas maneiras de estar e de agir perante estas crises. As geradas pelo atentado de 11 de setembro nos EUA (2001), a invasão do Afeganistão (2001), os bombardeamentos em Bali (2002), a Guerra do Iraque (2003), os atentados em Madrid (2004), o tsunami do Oceano Índico (2004), os atentados em Londres (2005), os atentados em França (2012, 2015 e 2016), na Bélgica (2014 e 2016), na Dinamarca (2015), na Turquia (2016) e na Alemanha (2016), pela sua dimensão, pelos seus impactos dramáticos no que concerne à perda de vidas humanas e aos danos materiais, assumiram tais proporçóes que ultrapassaram as fronteiras do seu epicentro, impondo uma reflexão política e operacional à escala global, na qual também o turismo foi visado. Inclusive a Primavera Árabe, com início em 2010, pelas ocorrências que lhe estiveram associadas, pelo número e perfil dos países onde se desenrolaram, e pela multidimensionalidade dos seus impactos, obrigaram a repensar a estratégia do turismo, porque alteraram significativamente os fluxos turísticos, privilegiando 
alguns países, não preparados para o efeito, em detrimento de outros em que o nível de insegurança e instabilidade, o real e o emocional aumentaram de forma acentuada.

A globalizaçáo, e em particular a globalização do Turismo, um processo que pode ser extremamente benéfico para a economia dos países, e sobretudo daqueles que têm investido crescentemente na produtização dos seus recursos e na sofisticação e na promoção da sua oferta, contribui para que algumas crises, aparentemente circunscritas a determinadas geografias se transformem rapidamente em crises mundiais, com as respetivas repercussōes.

O próprio conceito de crise turística, objeto de várias hipóteses, tem necessidade de ser repensado, perante as dinâmicas do mundo atual. Brent et al (2004), a partir do contributo de outros autores, debruçaram-se sobre a definição, mas igualmente sobre a gestáo e controlo e sobre o papel da comunicaçáo e do marketing nas proporçôes que assume e na forma como é gerida a crise.

Faulkner (2001: 136, apud Brent et al 2004: 5) faz a destrinça entre a "crise" e o "desastre" a partir do epicentro da sua ocorrência, classificando a crise como uma situação que é da responsabilidade da organização, da sua incapacidade de gestão e de adaptação à mudança; e o desastre como algo proveniente do ambiente externo, quando uma organização é confrontada com mudanças catastróficas imprevisíveis sobre as quais tem pouco ou nenhum controlo. Extrapolando esta classificação para os factos e para a escala que se constituem como objeto desta reflexão, podemos considerar que as crises estão relacionadas com as deficientes competências dos Estados para se gerirem e para se adaptarem às mudanças decorrentes da globalizaçáo e de outros fenómenos em curso no mundo atual, ao passo que os desastres decorrem de causas, como as naturais, sobre as quais náo existe controlo, ainda que determinadas decisóes e comportamentos de prevenção possam minimizar os impactos negativos que lhe estão subjacentes.

No caso do turismo, a ausência de planeamento estratégico, com uma abordagem prospetiva sobre um período temporal táo extenso quanto a imprevisibilidade e a imponderabilidade do sistema o permite, pode evitar, ou atenuar, determinadas crises, nomeadamente as inerentes à ação humana, preparando os 
destinos para os seus impactos negativos, mas igualmente para rentabilizar as oportunidades decorrentes da alteraçáo do comportamento da procura face aos territórios alvo de eventos geradores de instabilidade e insegurança. A título de exemplo, pode elencar-se a alteração de fluxos turísticos dos países envolvidos na Primavera Árabe, no que respeita a determinados produtos turísticos, do Norte de África e do Médio Oriente para países com um perfil de menor risco. Relativamente aos desastres, pela sua própria natureza imprevisível, nomeadamente os naturais, porque se trata de uma variável de difícil tratamento nos exercícios de prospetiva impostos pelo planeamento estratégico, existe uma dificuldade acrescida na sua integração neste exercício.

No que respeita à gestáo e ao controlo das crises, mas suas múltiplas dimensôes, mas também na de comunicação e marketing, Brent et al (2004: 7) entendem que é um fator crítico para o presente, mas sobretudo para o futuro das organizaçôes e dos territórios. A gestâo da comunicação e das perceçôes, através de uma estratégia de comunicação de crise, pode limitar a cobertura negativa por parte dos órgáos de comunicaçáo, gerindo as perceçóes junto da opiniâo pública durante a crise ou desastre e também na fase da recuperaçáo ou resolução. A abordagem conferida às informaçóes disponibilizadas por esta via ao público-alvo é fundamental para o controlo de danos no que respeita à imagem, um ativo estratégico na competitividade dos destinos turísticos. Nesta lógica, as competências comunicacionais e os conhecimentos de marketing, sáo fundamentais nos gestores de turismo, assim como as estratégias das organizaçôes relacionadas com estas dimensóes, aplicados a contextos de crise e de desastres.

Apesar da suscetibilidade do sistema e da indústria do turismo a crises externas e internas e a desastres, e da importância da imagem de destino no sucesso comercial e no comportamento da procura, continua a ser insuficiente a investigação que é feita sobre esta temática (Brent et al., 2004: 9), pelo que se impóe uma reflexão aprofundada de natureza teórica, mas, sobretudo, no nosso entender, uma investigação aplicada que permita, de forma eficiente, gerir as crises e os seus impactos, preparando os destinos turísticos para a nova realidade que se impóe à escala global, que não é espartilhada pelas fronteiras territoriais e que afeta, direta e indiretamente, o Turismo: o terrorismo. 
Bassil (2014: 669) entende que a indústria do turismo é o setor mais vulnerável e frágil da economia. A motivação dos turistas para visitar destinos turísticos é afetada negativamente cada vez que a segurança de um destino é comprometida por um ataque terrorista. De acordo com este autor, ainda que não exista uma definição universalmente aceite do que é "terrorismo" há elementos à maioria das definiçóes deste fenómeno, entre os quais se destacam a consecução de um objetivo de natureza política ou religiosa e a intenção de transmitir uma mensagem a um público muito mais vasto do que o constituído pelas suas vítimas diretas. No entanto, de acordo com este autor, pode existir coincidência conceptual e operacional entre os movimentos de resistência e as organizaçóes terroristas, dado que pode ser utilizado o mesmo modus operandi para diferentes fins.

Em países como o Líbano, Israel e Turquia, onde a indústria do turismo representa uma importante percentagem do PIB, os ataques terroristas podem contribuir para uma significativa desaceleração da economia. Por exemplo, quando o Líbano foi assolado por uma série de homicídios e de atentados contra figuras públicas, em 2005, a chegada de turistas internacionais sofreu uma redução de $10,7 \%$, e no ano subsequente de $6,7 \%$. Na década de 90 , também aconteceram vários ataques à bomba e tiroteios na Turquia, o que se traduziu numa redução de $20 \%$ no número previsto de turistas do Reino Unido em consequência destes ataques terroristas (Hall, 1995 apud Bassil, 2014:670). De igual forma, quando Israel, a partir de setembro de 2000, enfrentou uma onda de atentados suicidas após a deterioração do processo de paz com a Autoridade Palestiniana, iniciado em 1993 com o acordo de Oslo, o nível de estabilidade e segurança no país reduziu-se drasticamente, tendo-se sentido o seu efeito mais imediato e relevante no turismo, de acordo com Piterman (2000, apud Bassil, 2014: 670).

Bassil (2014) estuda o efeito dos ataques terroristas na procura turística do Líbano, Turquia e Israel através da análise do número de chegadas de turistas internacionais, partindo do pressuposto de que o terrorismo é um fator exógeno à procura turística. A escolha sobre estes casos de estudo é justificada pelo facto de serem países vizinhos, o que permite analisar se esta 
contiguidade territorial significa uma apropriação da quota de mercado ou se, pelo contrário, os impactos são negativos sobre o país vizinho. Por outro lado, a economia destes países é altamente dependente do turismo e, por último, a sua procura turística tem vindo a sofrer fortes oscilaçóes em consequência das atividades terroristas e da instabilidade vivida na região, tendo experimentado na década de noventa do século xx diferentes níveis de intensidade de atividade terrorista. Inovando relativamente a estudos anteriores pela classificação dos incidentes terroristas em função do seu epicentro (domésticos e internacionais), da sua intensidade, e da análise do estado da arte relativa a três diferentes países mediterrânicos (Líbano, Israel e Turquia), constata que o rápido crescimento do turismo nestes países tem tido inúmeros benefícios, económicos e sociais, mas que o setor se confronta com novos desafios, materializados nos ataques terroristas, nos ataques suicidas e nas guerras, que têm impactado negativamente no desenvolvimento do setor. Apesar disso, a literatura não evidencia claramente o impacto do turismo doméstico e transnacional na procura turística destes territórios. O autor, através da abordagem e da metodologia que desenvolve, conclui que: (1) o efeito do terrorismo no turismo depende do tipo de terrorismo e da sua intensidade; (2) existe um efeito significativo de contágio entre os três países, de natureza negativa, com exceção do Líbano para Israel e do Líbano para a Turquia, em que parece existir um efeito de substituição; (3) o maior efeito de contágio negativo é de Israel para os outros dois países; (4) os impactos negativos nos três países são distintos: o setor é mais afetado no Líbano do que na Turquia, mas é em Israel que assume uma maior dimensão, evidenciando uma sensibilidade acrescida dos turistas que viajam para o Médio Oriente para com a escalada de conflito entre Israel e a Palestina.

Em função das suas conclusôes, Bassil (2014) recomenda que os decisores políticos estabeleçam estratégias antiterroristas, pois a estabilidade e a segurança são fatores críticos de sucesso para o desenvolvimento turístico sustentável nestes territórios. Para além de que o comportamento de qualquer um destes países relativamente a estas variáveis tem repercussóes nos restantes dois, porque compartilham o mesmo mercado turístico. O autor recomenda também o desenvolvimento de investigação e de açóes transfronteiriças, pois a imagem 
ultrapassa os limites territoriais delimitados formalmente e o que está em causa, na decisão de viajar e na escolha do destino, que é um processo personalizado, é sobretudo a escala regional.

Na mesma linha, Bac et al (2015) consideram que a indústria do turismo é um dos motores mais potentes da economia global, e que numerosos países, sobretudo os emergentes e menos desenvolvidos, foram beneficiados com uma procura crescente de turistas internacionais. No entanto, nestes mesmos países os atos terroristas de grupos e organizaçóes locais contribuíram para uma imagem negativa do destino, funcionando como um fator de desmobilização dessa mesma procura. Num trabalho direcionado para a verificação da relação entre o turismo e o terrorismo, focado no mercado dos EUA, estes autores concluem que, regra geral, apesar dos esforços mundiais para reduzir a atividade dos grupos terroristas, a frequência destes atos é cada vez maior (Ross, 2006 apud Bac et al, 2015: 8) sobretudo devido às seguintes razóes: (1) a utilização do terrorismo como forma de protesto contra as injustiças protagonizadas pelos líderes políticos e pelos governos nacionais; (2) o patrocínio e apoio aos grupos terroristas por parte dos governos, como forma de evitar conflitos armados; (3) o fácil acesso dos terroristas às TIC's e às armas. Neste contexto, o aumento da segurança, através da qualificação e do aumento dos recursos policiais envolvidos e do recurso a equipamento de ponta é uma premência para as transportadoras aéreas, hotéis, restaurantes e outros prestadores de serviços na área do turismo, podendo ainda ser importante na preparação para fazer face a ataques biológicos (Bac et al, 2015: 8).

Estes autores concluem que a indústria do turismo de qualquer país se encontra exposta a atos terroristas, razão pela qual o planeamento com vista à recuperação, tangível e intangível, é um imperativo que pressupóe o envolvimento de todos os stakeholders com responsabilidades no setor, sejam os governantes à escala nacional, regional e local, as empresas, as universidades, seja a própria sociedade civil. No que diz respeito à recuperação após um desastre, existem duas perspetivas distintas sobre o conceito, no caso do desastre de 11 de setembro de 2001, por exemplo, os analistas do turismo tomaram como referência o ano de 2000, admitindo uma recuperação plena quando o número de chegadas de 
visitantes internacionais ultrapassar a registada antes do ataque terrorista. No entanto, os economistas têm uma abordagem diferente, entendendo que esta só tem lugar quando se alcançarem os valores antevistos para o destino, caso o ato náo se tivesse verificado. Esta última corrente pressupóe que no período pós-ataque o turismo terá que registar uma taxa de crescimento muito elevada e superior ao perspetivado, para atingir, num curto espaço de tempo, os valores à data do evento, acrescidos das tendências de crescimento anteriormente previstas (Bac et al, 2015: 9).

No entanto, e ainda de acordo com estes autores, as evidências mostram que, apesar dos impactos negativos do terrorismo na atividade turística, no longo prazo estes efeitos nefastos tendem a desvanecer-se, ocorrendo uma reposiçáo do interesse da procura. Destinos como a Irlanda do Norte, Egipto, Chipre, Grécia, Turquia, entre outros, onde ocorreu um decréscimo significativo da procura internacional em consequência dos ataques terroristas, viriam a registar posteriormente um número crescente de visitantes, ao ritmo da passagem do tempo (Baker, Coulter, 2007 apud Bac et al, 2015: 10). Nesta perspetiva, há também que referir que, de acordo com a OMT (2011), tanto os Estados Unidos como a Indonésia apresentaram taxas de crescimento impressionantes no período de recuperação, na ordem dos $4 \%$ e $9 \%$ ao ano, respetivamente. A OTTI (2014) refere que os EUA registam em 2006 o mesmo número de turistas internacionais que em 2000, náo conseguindo alcançar, ainda assim, o valor previsto, a partir da extrapolaçâo para o futuro da taxa média de crescimento dos dois anos anteriores ao atentado, caso este não se tivesse verificado.

Bac et al (2015:10) concluem, por último, que a realidade evidencia que uma gestão de crise eficiente e adequada é determinante para que qualquer destino turístico recupere de qualquer choque, seja este uma catástrofe natural ou um ataque terrorista, embora reconhecendo que o terrorismo é crescentemente um dos maiores problemas do turismo à escala global (Bac et al, 2015:10).

Também Baker (2014:58) considera que o terrorismo pode impactar na indústria das viagens e do turismo em várias dimensōes e de forma extremamente significativa, nomeadamente contribuindo para o desemprego, para a deflação e para inúmeros outros problemas sociais e económicos, potenciados 
pela extrema relevância que o setor assume em inúmeras economias à escala global. Os efeitos fazem-se sentir através dos setores que estão intimamente ligados ao turismo, como o transporte aéreo, o alojamento, a restauração e noutros que são operadores diretos, mas igualmente nos que, ainda que de forma indireta, contribuem para a diversidade e para a diferenciação da oferta dos destinos e, consequentemente, para a sua capacidade de atração e para a sua competitividade. De acordo com este autor, o rápido crescimento da indústria do turismo é uma consequência direta do forte crescimento económico verificado em anos transatos, do aumento do rendimento disponível e do tempo de lazer, do aumento da mobilidade, do sucesso da promoção turística, e do reconhecimento por parte dos governos da relevância do papel do turismo na economia dos países. Apesar das previsões otimistas para os próximos dez anos, para a maioria dos destinos, com taxas de taxas de crescimento mais elevadas do que em qualquer outro setor, estas só serão concretizáveis através da capitalização da motivação para a viagem dos indivíduos, da valorização dos recursos turísticos, da qualificação dos recursos humanos, da criação de um clima favorável ao investimento e à procura, através da atuação dos governos na promoção da segurança, da facilidade e no apoio ao investimento, e na simplificação das políticas fiscais. Mas para além de todas estas variáveis, um dos maiores desafios para o turismo atualmente é o terrorismo e a turbulência política, até pela sua relevância económica e pela deslocação de pessoas que pressupóe, condicionando o comportamento da procura, o seu crescimento e a sustentabilidade dos destinos (Baker, 2014:64).

\section{$A(s)$ influência(s) do terrorismo no comportamento da procura turística}

A decisão de viajar, as motivaçóes, a escolha do destino é um processo individual, embora também muito influenciado pelo comportamento coletivo. $\mathrm{Na}$ atualidade, a valorização da segurança estimula o turista a procurar destinos que se afigurem estáveis e com menor propensão para catástrofes naturais, mas sobretudo com risco reduzido de ataques terroristas. A imagem 
negativa de um destino, relativamente a esta variável, tem um forte impacto na procura sobretudo no imediato, redirecionando os fluxos turísticos. Evidentemente que o perfil do turista (idade, género, estrato socioeconómico...) é determinante na relevância que confere a estas questôes, tal como o facto de viajar sozinho ou integrado em grupos. O turista que viaja com a família, sobretudo quando o agregado familiar é composto também por crianças, tende a sobrevalorizar as questóes da segurança, do acesso a cuidados médicos e da acessibilidade. Também o turista sénior é mais sensível a estas características dos destinos, enquanto os pertencentes a grupos etários mais jovens tendem a privilegiar outros aspetos, ainda que possam náo descurar completamente estes fatores.

Seabra et al (2014: 874), com base numa amostra de 600 turistas internacionais viajantes em Portugal, Espanha e Itália, realizaram um estudo sobre as principais questóes relacionadas com o terrorismo, a perceção do risco e a preocupação com a segurança dos turistas internacionais, que lhes permitiu concluir que os turistas se sentem crescentemente motivados a obter informaçáo sobre terrorismo nos meios de comunicação, um comportamento que revela o seu interesse sobre este tema e que influencia diretamente a sua perceção sobre o risco e a sua preocupação com a segurança. De acordo com estes autores, esta perceçáo condiciona o planeamento da viagem, nomeadamente no que concerne à escolha do destino.

Os resultados deste estudo, realizado com o objetivo de analisar o comportamento do consumidor no mercado de turismo, com base no pressuposto de que o terrorismo pode condicionar a decisão de realizar viagens internacionais, evidenciam que o terrorismo influencia a perceção do risco que os turistas associam às viagens internacionais, ainda que não confirmem que o contacto direto ou indireto com as crises geradas por estes eventos tenha um impacto significativo sobre esta mesma perceção. Paralelamente, o conhecimento prévio sobre o terrorismo, obtido através dos media, é um antecedente significativo na perceção do risco em viagens internacionais, evidenciando o efeito importante dos meios de comunicação nas perceçóes dos turistas e na imagem construída em torno dos destinos (Seabra et al, 2014: 891). 
Um estudo realizado pela IPK Internacional (2016) para a Feira Turística ITB Berlim, conclui que, ainda que o entusiamo pelas viagens internacionais não esteja comprometido, a ameaça de terrorismo influencia significativamente o planeamento das férias, embora a imagem associada aos diferentes destinos varie significativamente em função da sua propensão para ataques terroristas. A Figura 3 representa graficamente o nível de alerta dos destinos, em função do risco de ataques terroristas no verão de 2016, sendo percetível o comportamento díspar dos diferentes países, bem como classificação mais elevada nos países onde já ocorreram atentados terroristas, onde se desenrolam guerras ou onde se encontram localizados geograficamente os grupos que reivindicam a maioria dos atentados, nomeadamente o autoproclamado Estado Islâmico e a Al-Qaeda.

O estudo anteriormente referido conclui que a ameaça de terrorismo influencia o comportamento de viagem de $40 \%$ dos turistas internacionais, embora os resultados variem significativamente em função do mercado emissor. Os sul-americanos, escandinavos e holandeses afirmaram que a ameaça do terrorismo irá afetar o seu comportamento de viagem, enquanto os asiáticos e europeus orientais estão sobretudo influenciados pelas ocorrências do presente.

Foram igualmente observadas diferenças entre os vários segmentos do viajante. Aqueles com crianças são mais sensíveis a esta questão, enquanto os grupos etários mais jovens e os solteiros afirmam-se apenas relativamente impressionados com os alertas terroristas.

Esta pesquisa também analisou a influência da ameaça do terrorismo na mudança do comportamento de viagem. No que respeita a esta variável, 15\% dos turistas internacionais afirmaram que vão evitar viajar para o exterior em 2016, optando por passar as férias no seu país de origem. Um dos exemplos mais ilustrativos desta realidade é a Alemanha que, no verão de 2016, voltará a ser o destino de férias preferido dos alemães.

Um quarto dos turistas internacionais disseram que pretendem continuar a viajar para o exterior, ainda que para destinos que percecionam como seguros. Os destinos entendidos como menos seguros, de acordo com a informação disponibilizada pelos entrevistados, foram os que no passado já registaram 


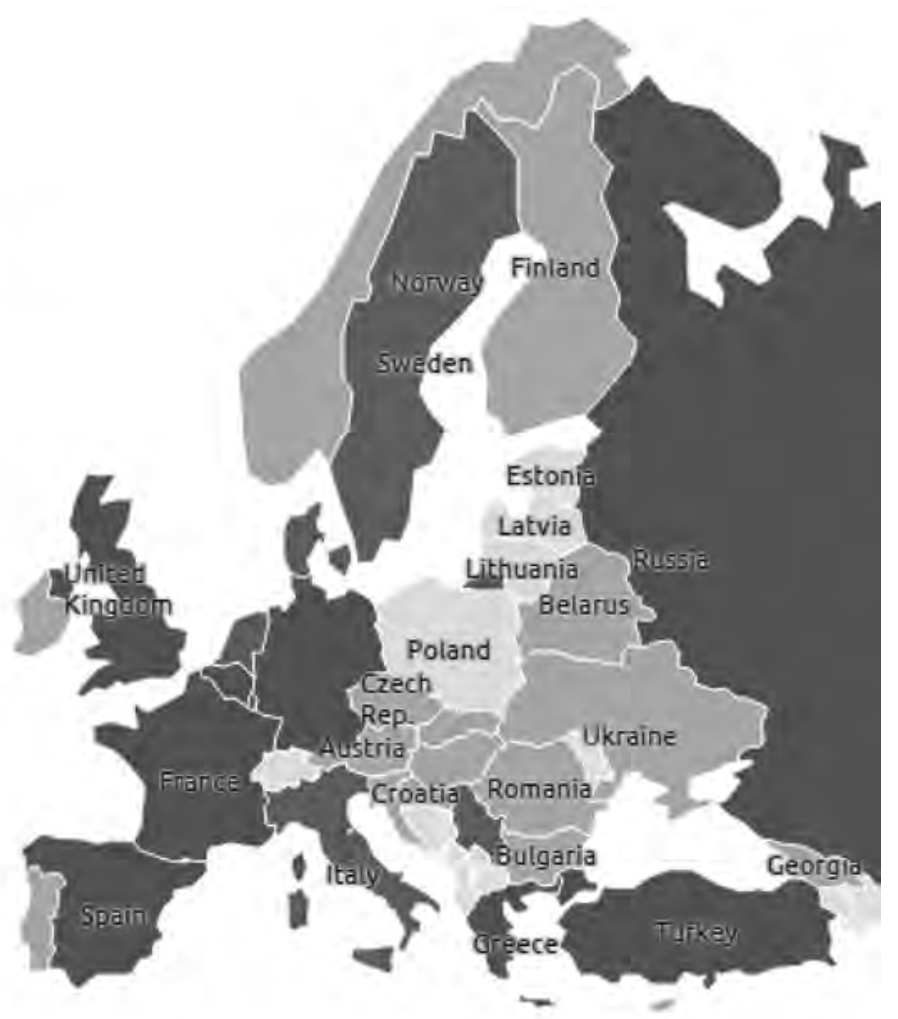

Nível 4 - países com risco elevado

Nível 3 - países com risco médio

Nivel 1-2 - países com risco subjacente

Figura 3

Nível de alerta dos destinos, em função do risco de ataques terroristas no verão de 2016

Fonte: Foreign Office, Reino Unido, 2016.

ataques terroristas ou eventos similares. Uma análise comparativa à escala global permite concluir que Israel, a Turquia e o Egipto são os países considerados menos apelativos, sendo que a má imagem de um destino afeta também os territórios vizinhos, independentemente de se afigurarem, ou não, epicentro de incidentes. 


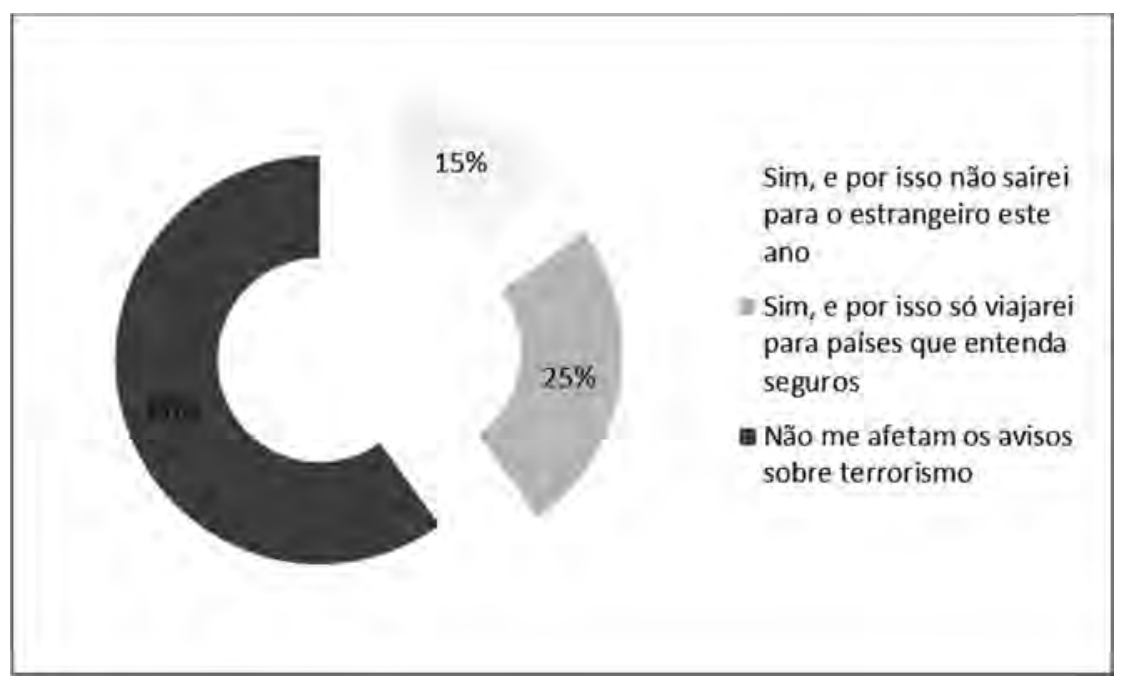

Figura 4

Influência da ameaça de terrorismo sobre o comportamento de viagem

Fonte: IPK para ITB Berlin. Amostra: 50.000 pessoas de 40 mercados emissores que viajaram no último ano para o estrangeiro.

Uma outra conclusão permitida por este estudo, é a de que em 2016 o comportamento da procura turística se altera significativamente. Alguns países como a Turquia, Tunísia, Marrocos, Egito, Jordânia e Israel vão confrontar-se com uma acentuada redução na sua procura turística internacional. Em contrapartida, outros destinos como o Canadá, a Austrália, a Escandinávia e a Suíça apresentam boas perspetivas de crescimento, apesar da ameaça global do terrorismo (IPK Internacional, 2016).

\section{Conclusốes}

As vivências num mundo globalizado estão associadas a um conjunto de múltiplas oportunidades mas também de ameaças. A proximidade física 
e virtual, viabilizada pelas TIC's e pela crescente mobilidade, dão forma ao conceito de Aldeia Global, permitindo a consecução de objetivos individuais e coletivos motivados por princípios e sentimentos contextualizados numa escala em que o Bem e o Mal são os extremos. As consequências económicas, sociais e culturais subjacentes a esta realidade impóem uma adaptação contínua a mudanças e desafios que assumem as proporçóes que lhe são conferidas por esta nova escala.

O Turismo é um setor com uma crescente relevância na economia global, constituindo a motivação para a deslocação anual de milhóes de pessoas, gerando receitas, postos de trabalho e impondo a afirmaçáo contínua das identidades dos territórios perante uma acentuada tendência para a uniformização. Pelas suas características, encontra-se fortemente exposto a crises, como as provocadas pelos ataques terroristas, como as catástrofes naturais, sendo fundamental a sua gestão eficiente para recuperar os destinos e a sua imagem.

A análise do estado da arte e a objetividade dos números que caracterizam a atualidade não permitem uma conclusão diferente da que aponta no sentido de uma relaçáo direta entre o turismo e o terrorismo, sendo que a complexidade deste último fenómeno dificulta a avaliação plena dos impactos, pela natureza intangível de alguns, mas também porque para além dos diretos, os indiretos são dificilmente delimitáveis e mensuráveis.

O terrorismo impacta negativamente no turismo dos territórios que se afiguram como o seu epicentro, e as ondas de repercussão ultrapassam largamente as fronteiras legais. Para além das suas consequências ao nível da perda de vidas humanas e dos prejuízos materiais, o seu contributo para a desconstrução da imagem positiva dos destinos é um dos danos mais incontroláveis e que mais se perpetua no tempo. A capacidade dos inúmeros atores diretamente relacionados com o planeamento e a gestão do Turismo para gerir as crises, nomeadamente na dimensão da comunicação e do marketing é determinante para a recuperação tangível e intangível do destino.

Se para os territórios alvo de atentados o Turismo apenas tem impactos negativos, para outros destinos, com oferta turística semelhante ou até distinta, estes eventos podem constituir uma oportunidade. A realidade tem evidenciado 
que as crises e os desastres, independentemente da sua natureza, têm um papel determinante na alteração dos fluxos turísticos. Perante a decisão de viajar, os turistas na busca de destinos mais seguros e estáveis direcionam a sua atenção para territórios que até então não tinham exercido sobre eles a sua capacidade de atração. A relação entre o preço e a oferta turística tende a perder protagonismo num cenário de valorização da integridade física e psicológica.

O planeamento estratégico revela-se fundamental na preparação dos destinos para fazer face aos desafios colocados pela globalização, permitindo potenciar as oportunidades que lhe estão subjacentes e prevenir e minimizar as ameaças, nomeadamente as configuradas pelo terrorismo.

\section{Referências bibliográficas}

Bac, D. P.; Bugnar, N. G. ; Mester, L. E. (2015). Terrorism and its Impacts on the Tourism Industry. Revista Românã de Geografie Politicã, 1:5-11.

Baker, D. (2014). The Effects of Terrorism on The Travel and Tourism Industry. International Journal of Religious Tourism and Pilgrimage, 2(1):58-67.

Bassil, C. (2014). The Effect of terrorism on Tourism Demand in the Middle East. Peace Economics, Peace Science and Public Policy, 20(4): 669-684.

Bentley, T. A. and Page, S. J. (2001). Scoping the extent of adventure tourism accidents. Annals of Tourism Research, 28 (3): 705-726.

Brent W. R., Dorrell, H. Miller, D., and Miller, G. A. (2004) Crisis Communication and Recovery for the Tourism Industry. Journal Of Travel \& Tourism Marketing, 15 (2-3).

Font, J. N. E Rufí, J. V. (2006). Geopolítica, Identidade e Globalização. Săo Paulo: Annablume.

IPK - International (2016). Tourism in Times of Terror - Press Release. http://www.ipkinternational. com/. Acesso em 01-09-2016.

Lee, Y. and Harrald, J. (1999). Critical issue for business area impact analysis in business crisis management: Analytical capability. Disaster Prevention and Management, 8 (3): 184-189.

McLuhan, M. (1972). A galáxia de Gutenberg; a formação do homem tipográfico. São Paulo: Editora Nacional, Editora da USP.

Seabra, C. ; Abrantes, J. L.; Kastenholz, E. (2014). The influence of terrorism risk perception on purchase involvement and safety concern of international travelers. Journal of Marketing Management, 30 (9-10):874-903.

Tymothy, D. J. (2006). Safety and Security Issues in Tourism. In C. Costa and D. Buhalis, Tourism management dynamics - trends, management and tools. Oxford: Elsevier, 19-27.

WTO - World Tourism Organization (2016). Tourism Highlights - 2016 Edition. http://mkt. unwto.org. Acesso em 01-08-2016. 